\title{
Expression of immunoglobulin $G$ in human podocytes, and its role in cell viability and adhesion
}

\author{
ZIYANG JING ${ }^{1}$, HUI DENG $^{2}$, JUNFAN MA ${ }^{3}$, YANHONG GUO ${ }^{1}$, YAOXIAN LIANG $^{4}$, RUI WU $^{5}$, \\ LATA A $^{1}$, ZIHAN GENG ${ }^{3}$, XIAOYAN QIU ${ }^{3 *}$ and YUE WANG ${ }^{1 *}$ \\ ${ }^{1}$ Department of Nephrology, Peking University Third Hospital, Beijing 100191; ${ }^{2}$ Department of Nephrology, \\ Peking University First Hospital, Beijing 100034; ${ }^{3}$ Department of Immunology, Key Laboratory of Medical Immunology, \\ Ministry of Health, School of Basic Medical Sciences, Peking University, Beijing 100191; \\ ${ }^{4}$ Department of Nephrology, Peking University People's Hospital, Beijing 100044; \\ ${ }^{5}$ Department of Pathology, Peking University Third Hospital, Beijing 100191, P.R. China
}

Received December 21, 2016; Accepted January 18, 2018

DOI: $10.3892 / \mathrm{ijmm} .2018 .3525$

\begin{abstract}
Podocyte injury occurs during the initiation and development of numerous forms of glomerular disease, and antibodies targeting podocytes have become a biomarker for diagnosis and monitoring treatment response. Accumulating evidence has suggested that immunoglobulin (Ig) is expressed in non-B lineage cells, including epithelial cancer cells, myeloid cells and several types of normal cells. The main aim of the present study was to ascertain the expression of $\operatorname{IgG}$ in human podocytes and to determine its potential role in cellular bioactivity. The present study detected positive staining for $\operatorname{IgG}$ heavy chain $(\operatorname{Ig} \gamma)$ and its subtype $\gamma 4$, and the light chains $\kappa$ and $\lambda$ in the cytoplasm or on the membrane by immunofluorescence. In addition, positive bands were detected for $\operatorname{Ig} \gamma, \gamma 1$, $\gamma 3, \gamma 4, \kappa$ and $\lambda$ in the lysates of a podocyte cell line by western blotting. Mass spectrometry confirmed IgG1 as an intact tetramer in the culture supernatant. Constant region transcripts of $\operatorname{Ig} \gamma, \gamma 1, \gamma 3, \gamma 4, \kappa$ and $\lambda$ were identified by reverse transcription-polymerase chain reaction, and DNA sequencing of these
\end{abstract}

Correspondence to: Professor Yue Wang, Department of Nephrology, Peking University Third Hospital, 49 Huayuanbei Road, Beijing 100191, P.R. China

E-mail: bjwangyue@sina.com

Professor Xiaoyan Qiu, Department of Immunology, Key Laboratory of Medical Immunology, Ministry of Health, School of Basic Medical Sciences, Peking University, 38 Xueyuan Road, Beijing 100191, P.R. China

E-mail: qiuxy2014@163.com

${ }^{*}$ Contributed equally

Abbreviations: RAG, recombination activating gene; AID, activation-induced cytidine deaminase; SAC, Staphylococcus aureus; $\mathrm{MN}$, membranous nephropathy

Key words: human podocyte, immunoglobulin G, glomerular disease, $\mathrm{V}(\mathrm{D}) \mathrm{J}$ rearrangement, membranous nephropathy transcripts revealed $96-99 \%$ similarity with Ig mRNAs in the National Center for Biotechnology Information database. Compared with the diverse gene rearrangements from $\mathrm{B}$ cell-derived Ig, podocyte-derived Ig exhibited conservative $\mathrm{V}(\mathrm{D}) \mathrm{J}$ patterns in the variable regions of $\operatorname{Ig} \gamma$ and $\kappa$ chains. Furthermore, the present study investigated the mechanism underlying IgG production in these cells by examining the expression of recombination activating gene (RAG)1, RAG2 and activation-induced cytidine deaminase. The expression levels of these proteins suggested that podocyte-derived Ig and traditional Ig may be generated in a similar manner. Furthermore, small interfering RNA-mediated downregulation of $\mathrm{IgG}$ expression reduced podocyte viability and adhesive capabilities. These findings suggested that $\mathrm{IgG}$ is expressed in podocytes and that this expression may be associated with podocyte function. Due to its potential biological and clinical significance, this phenomenon warrants further investigation.

\section{Introduction}

Podocytes, also known as visceral epithelial cells, are terminally differentiated cells of the kidney glomerulus, which have a key role in glomerular development and maintenance (1). The cytoskeletal dynamics and structural plasticity of podocytes, as well as the function of received and transmitted signals, are important for glomerular filtration and thus for renal function. Furthermore, podocyte injury participates in the occurrence and development of human and experimental glomerular diseases (2), among which, membranous nephropathy (MN) is recognized as an organ-specific autoimmune disease, which is well known to be associated with podocyte injury (3). The subepithelial immune complexes in $\mathrm{MN}$ in renal tissue immunofluorescence have been reported to contain circulating autoantibodies, intrinsic podocyte antigens (4) and complement components. Serum autoantibodies to phospholipase-A2-receptor have been suggested not only to be crucial in the advancement of $\mathrm{MN}$, but also to act as a biomarker for diagnosis, disease activity and treatment efficiency (5). 
Antibodies, also known as immunoglobulins (Igs), are expressed by B lymphocytes; however, accumulating evidence has indicated that Igs, including IgG, IgA and $\mathrm{IgM}$, are produced in non-B lineage cells, such as epithelial cancer cells (6-9) and leukemic cells (10-12). Furthermore, several types of normal cells, including germ cells $(13,14)$, neurons $(15,16)$, endothelial cells (17) and skin epidermal cells (18), can also express Igs. Although non-B cell-derived Ig and traditional Ig have some similar characteristics, the former possesses unique characteristics, particularly with regards to structure and function. In contrast to the diversity of the Ig variable region, non-B cell-derived Ig tends to exhibit specific or restricted usage of certain sequences $(11,19)$. It has a unique glycosylation profile, through which the RP215 monoclonal antibody $(\mathrm{mAb})$ can recognize non-B cell-derived $\operatorname{Ig}(20,21)$. According to the results of previous studies, these Igs are essential for cell vitality and proliferation $(6,22-24)$, and are also associated with the migration, invasiveness and metastasis of cancer cells, thus suggesting that non-B Igs participate in tumorigenesis and development $(25,26)$. Furthermore, the regulatory mechanisms of gene expression have been explored in several studies (27-29).

The present study aimed to explore the expression of $\operatorname{IgG}$ in podocytes, and demonstrated that human podocytes may express and secrete IgG. In addition, not only was transcription of the constant region detected, V(D)J rearrangement of the variable region was demonstrated, and the expression levels of certain proteins were verified. Furthermore, the results suggested that podocyte-derived IgG may participate in the maintenance of cell morphology and growth.

\section{Materials and methods}

Podocyte culture. The conditionally immortalized human podocyte cell line was previously established, as reported in a previous study (30), and was donated by Professor Moin A. Saleem (Children's Renal Unit and Academic Renal Unit, University of Bristol, Bristol, UK). The study was approved by the ethics committee of Peking University Third Hospital (approval document issued on February 17th, 2016; under no. 053). The cells were cultured under growth-permissive conditions in RPMI-1640 medium (Gibco; Thermo Fisher Scientific, Inc., Waltham, MA, USA) supplemented with $1 \%$ insulin-transferrin-selenium-A supplement (ITS; Gibco; Thermo Fisher Scientific, Inc.), $100 \mathrm{U} / \mathrm{ml}$ penicillin, $0.1 \mathrm{mg} / \mathrm{ml}$ streptomycin (Gibco; Thermo Fisher Scientific, Inc.) and 10\% fetal bovine serum (FBS; Australian origin; Biological Industries USA, Cromwell, CT, USA) at $33^{\circ} \mathrm{C}$. Podocytes were then incubated at $37^{\circ} \mathrm{C}$ without ITS for 10-14 days for differentiation; these cells were used for subsequent experiments. Protein and mRNA samples were collected from podocytes after $48 \mathrm{~h}$ stimulation with or without Staphylococcus aureus (SAC; Sigma-Aldrich; Merck $\mathrm{KGaA}$, Darmstadt, Germany) at $37^{\circ} \mathrm{C}$.

Immunofluorescence. The podocytes were cultured on coverslips, which were fixed in $4 \%$ paraformaldehyde for $30 \mathrm{~min}$ at room temperature. Subsequently, $0.2 \%$ Triton X-100 was used to permeabilize the cells for $15 \mathrm{~min}$ at room temperature. The slides were washed in PBS and blocked with $5 \%$ bovine serum albumin (BSA; Invitrogen; Thermo Fisher Scientific, Inc.) at room temperature for $30 \mathrm{~min}$, after which they were incubated with primary antibodies at $4^{\circ} \mathrm{C}$ overnight. The antibodies used were as follows: Rabbit anti-human IgG heavy chain $(\operatorname{Ig} \gamma)$ (ab109489; 1:150), anti-human Igא (ab134929; 1:250), anti-human $\operatorname{Ig} \lambda($ ab124719; 1:250) (all from Abcam, Cambridge, MA, USA), mouse anti-human Ig $\gamma 4$ (GI-0910; 1:200; Beijing Xiya Golden Bridge Biotechnology Co., Ltd., Beijing, China), rabbit anti-human F-actin (bs-1571R; 1:500; Beijing Bioss Biotechnology Co., Ltd., Beijing, China) and RP215 mAb (dilution, 1:200; donated by Professor Xiaoyan Qiu, Peking University, Beijing, China), which specifically identified a carbohydrate-associated epitope on non-B cell-derived Ig $\gamma$. PBS was used as a negative control. After washing in PBS, the slides were incubated with fluorescein isothiocyanate-labeled goat anti-rabbit (ZF-0311; 1:200) or goat anti-mouse IgG antibodies (ZF-0312; 1:200) (both from Beijing Zhongshan Golden Bridge Biotechnology Co., Ltd., Beijing, China) at room temperature for $1 \mathrm{~h}$. Nuclei were stained with DAPI (C0060; $15 \mu \mathrm{g} / \mathrm{ml}$; Beijing SUOLAIBAO Biotechnology Co., Ltd., Beijing, China). Images were captured under a Leica DFC300 FX fluorescence microscope (Leica Microsystems GmbH, Wetzlar, Germany).

Protein extraction and western blotting. Podocytes were lysed in TSD lysis buffer (1\% SDS, $50 \mathrm{mM} \mathrm{pH} \mathrm{7.5} \mathrm{Tris-HCL,}$ $50 \mathrm{mM}$ DTT) containing protease inhibitors (Applygen Technologies Inc., Beijing, China). Total protein concentrations were measured using a bicinchoninic acid kit (Applygen Technologies Inc.). Following centrifugation at $12,000 \mathrm{x} \mathrm{g}$ for $10 \mathrm{~min}$ at $4^{\circ} \mathrm{C}$, the lysate supernatants were prepared for western blotting. Human serum (obtained from one of the authors, female, 26 years old) enriched with Igs was used as a positive control. The cell supernatant was purified by affinity chromatography using protein $G$ sepharose; the target protein was purified according to the manufacturer's protocol (R8300; Beijing SUOLAIBAO Biotechnology Co., Ltd.). The protein samples then underwent SDS-PAGE, western blot analysis and mass spectrometry, which was conducted by Beijing Protein Innovation (Beijing, China).

Western blotting was carried out according to standard procedures. Briefly, lysate proteins were separated by 10\% SDS-PAGE and were transferred onto a nitrocellulose membrane. Subsequently, the membrane was blocked in 5\% BSA (Amresco, LLC, Solon, OH, USA) and was incubated with primary antibodies at $4^{\circ} \mathrm{C}$ overnight, including rabbit anti-human Ig $\gamma($ ab109489; 1:1,000), rabbit anti-human $\operatorname{Ig} \gamma 1$ (ab108969; 1:1,000), rabbit anti-human Ig 2 (ab134050; 1:10,000), rabbit anti-human $\operatorname{Ig} \gamma 3$ (ab109761; 1:5,000), rabbit anti-human $\operatorname{Ig} \gamma 4$ (ab109493; 1:5,000) and anti-Ig $\lambda(a b 124719$; $1: 20,000)$, rabbit anti-human $\beta$-actin (ab8227; $1: 2,000)$, rabbit anti-human GAPDH (ab181602; 1:10,000) (all from Abcam), mouse anti-human Igא (GTX21050; GeneTex, Inc., Irvine, CA, USA) and RP215 mAb. The membrane was then incubated with goat anti-rabbit (cat. no. 926-32211) or anti-mouse (cat. no. 926-32210) IgG-IRDyeTM680CW secondary antibodies (1:10,000; LI-COR Biosciences, Lincoln, NE, USA) at room temperature for $1 \mathrm{~h}$. The results were analyzed using an Odyssey Infrared imager and Odyssey V3.0 software (LI-COR Biosciences). 
Table I. Sequences of polymerase chain reaction primers used in the present study.

\begin{tabular}{|c|c|c|c|}
\hline Gene name & Primer & Primer sequence $\left(5^{\prime}-3^{\prime}\right)$ & $\begin{array}{l}\text { Product length } \\
\text { (bp) }\end{array}$ \\
\hline $\operatorname{Ig} \mathrm{V} \gamma$ & $\begin{array}{l}\text { External antisense } \\
\text { Internal antisense } \\
\text { Internal antisense }\end{array}$ & $\begin{array}{l}\text { VH1:GAGGTGCAGCTCGAGGAGTCTGGG } \\
\text { VH2:CAGGTGCAGCTCGAGCAGTCTGGG } \\
\text { VH3:CAGGTACAGCTCGAGCAGTCAGG } \\
\text { VH4:CAGGTGCAGCTGCTCGAGTCGGG } \\
\text { CH1:ACACCGTCACCGGTTCGG } \\
\text { FR2:TGGRTCCGVCAGSCYCCNGG } \\
\text { JH:AACTGCAGAGGAGACGGTGACC }\end{array}$ & $280-300$ \\
\hline $\operatorname{Ig} V_{\kappa}$ & $\begin{array}{l}\text { External sense } \\
\text { External antisense } \\
\text { Internal sense } \\
\text { Internal antisense }\end{array}$ & $\begin{array}{l}\text { GACATCGAGCTCACCCAGTCTCC } \\
\text { CGGGAAGATGAAGACAGATGGTGC } \\
\text { GAAATTGAGCTCACGCAGTCTCCA } \\
\text { TGGTGCAGCCACAGTTCGTT }\end{array}$ & $340-360$ \\
\hline $\operatorname{Ig} C \gamma$ & $\begin{array}{l}\text { Sense } \\
\text { Antisense }\end{array}$ & $\begin{array}{l}\text { AGGACTCTACTCCCTCAGCAG } \\
\text { TCAGGCTGACCTGGTTCTTG }\end{array}$ & 566 \\
\hline $\operatorname{Ig} \mathrm{C} \kappa$ & $\begin{array}{l}\text { Sense } \\
\text { Antisense }\end{array}$ & $\begin{array}{l}\text { TGAGCAAAGCAGACTACGAGA } \\
\text { GGGGTGAGGTGAAAGATGAG }\end{array}$ & 231 \\
\hline $\operatorname{Ig} C \lambda$ & $\begin{array}{l}\text { Sense } \\
\text { Antisense }\end{array}$ & $\begin{array}{l}\text { GGGACCAAGCTCACCGTCCTAG } \\
\text { TCTTCTCCACGGTGCTCCCTTC }\end{array}$ & 316 \\
\hline $\operatorname{Ig} C \gamma 1$ & $\begin{array}{l}\text { Sense } \\
\text { Antisense }\end{array}$ & $\begin{array}{l}\text { GGGCTTCCAAGCCAACAGGGCAGGACA } \\
\text { GTTTTGTCACAAGATTTGGGCTC }\end{array}$ & 603 \\
\hline $\operatorname{Ig} C \gamma 2$ & $\begin{array}{l}\text { Sense } \\
\text { Antisense }\end{array}$ & $\begin{array}{l}\text { GGGCTTCCAAGCCAACAGGGCAGGACA } \\
\text { GTGGGCACTCGACACAACATTTGCG }\end{array}$ & 597 \\
\hline $\operatorname{Ig} C \gamma 3$ & $\begin{array}{l}\text { Sense } \\
\text { Antisense }\end{array}$ & $\begin{array}{l}\text { AGGTGGGCAGGCTTCAGGCACCGAT } \\
\text { TTGTGTCACCAAGTGGGGTTTTGAGC }\end{array}$ & 670 \\
\hline $\operatorname{Ig} C \gamma 4$ & $\begin{array}{l}\text { Sense } \\
\text { Antisense }\end{array}$ & $\begin{array}{l}\text { GATGGCGTGGAGGTGCATAA } \\
\text { GTGTACACCTGTGGCTCTCG }\end{array}$ & 212 \\
\hline AID & $\begin{array}{l}\text { Sense } \\
\text { Antisense }\end{array}$ & $\begin{array}{l}\text { GAGGCAAGAAGACACTCTG } \\
\text { GTGACATTCCTGGAAGTTGC }\end{array}$ & 647 \\
\hline RAG1 & $\begin{array}{l}\text { External sense } \\
\text { External antisense } \\
\text { Internal sense } \\
\text { Internal antisense }\end{array}$ & $\begin{array}{l}\text { TGGATCTTTACCTGAAGATG } \\
\text { CTTGGCTTTCCAGAGAGTCC } \\
\text { CACAGCGTTTTGCTGAGCTC } \\
\text { AGCTTGCCTCAGGGTTCATG }\end{array}$ & 327 \\
\hline RAG2 & $\begin{array}{l}\text { External sense } \\
\text { External antisense } \\
\text { Internal sense } \\
\text { Internal antisense }\end{array}$ & $\begin{array}{l}\text { TGGAAGCAACATGGGAAATG } \\
\text { CATCATCTTCATTATAGGTGTC } \\
\text { TTCTTGGCATACCAGGAGAC } \\
\text { CTATTTGCTTCTGCACTG }\end{array}$ & 193 \\
\hline CD19 & $\begin{array}{l}\text { Sense } \\
\text { Antisense }\end{array}$ & $\begin{array}{l}\text { AAGGGGCCTAAGTCATTGCT } \\
\text { CACGTTCCCGTACTGGTTCT }\end{array}$ & 347 \\
\hline$\beta$-actin & $\begin{array}{l}\text { Sense } \\
\text { Antisense }\end{array}$ & $\begin{array}{l}\text { AGAGCTATGAGCTGCCTGAC } \\
\text { AATTGAATGTAGTTTCATGGATG }\end{array}$ & 121 \\
\hline
\end{tabular}

AID, activation-induced cytidine deaminase; C, constant; CD19, cluster of differentiation 19; Ig, immunoglobulin; RAG, recombination activating gene; $\mathrm{V}$, variable.

Isolation of peripheral blood mononuclear cells (PBMCs). Mononuclear cells were prepared from the peripheral blood of a healthy person (author of the present study as mentioned above). PBMCs were isolated using Ficoll-Paque PLUS
(GE Healthcare, Chicago, IL, USA) by density-gradient centrifugation. The cells from the interface of the solution were considered PBMCs, which were collected and washed in PBS. The isolated PBMCs were immediately utilized. 
Reverse transcription-polymerase chain reaction (RT-PCR). Total RNA was extracted from podocytes and PBMCs according to a standard procedure using TRIzol reagent (Invitrogen; Thermo Fisher Scientific, Inc.). RNA concentration was estimated using a NanoDrop spectrophotometer (NanoDrop Technologies; Thermo Fisher Scientific, Inc., Wilmington, DE, USA). Subsequently, RT was performed with oligo(dT) primer using GoScript ${ }^{\mathrm{TM}}$ Reverse Transcriptase (Promega Corporation, Madison, WI, USA) according to the manufacturer's protocol. Transcripts of the $\operatorname{Ig} \gamma, \operatorname{Ig} \kappa, \operatorname{Ig} \lambda$ and I $\gamma$-C $\gamma$ constant regions (31) were amplified by PCR using Taq PCR MasterMix (Beijing Biomed Biotechnology Co., Ltd., Beijing, China). Transcripts of the $\operatorname{Ig} \gamma$ and $\operatorname{Ig} \kappa$ variable regions were amplified by semi-nested PCR with Taq PCR MasterMix (Biomed). The PCR products were separated by electrophoresis on a $1.5 \%$ agarose gel at a constant voltage of $120 \mathrm{~V}$ for $40-50 \mathrm{~min}$. The thermocycling conditions were as mentioned in previous studies $(6,18)$.

To detect the mRNA expression levels of recombination activating gene (RAG)1 and RAG2, a nested RT-PCR assay was used (32). Total RNA was treated with RQ1 RNase-free DNase (Promega Corporation) to eliminate the contamination of genomic DNA. The cDNA template was replaced with treated RNA as a negative control. For amplification of activation-induced cytidine deaminase (AID), the primer sequences and protocol were used as previously described (33). Details of the primer sequences used in the present study are listed in Table I. The reliability of PCR products was analyzed by DNA sequence analysis, which was performed by Invitrogen Trading (Shanghai) Co., Ltd. (Shanghai, China).

Analysis of rearrangement gene. PCR products of the $\operatorname{Ig} \gamma$ and $\operatorname{Ig} \kappa$ variable regions obtained from both PBMCs and podocytes were respectively cloned into a pGEM-T Easy Vector System I (A1360; Promega Corporation), which was transfected into Competent Escherichia coli TOP10 cells (Tiangen Biotech Co., Ltd., Beijing, China). The transfection experiments were performed according to the manufacturer's protocols. Briefly, ligation reactions were set up using transfection reagents in pGEM-T Easy Vector System I and the transformations were performed using the ligation reactions. Subsequently, clones were formed and amplified through the proliferation of bacteria. Following DNA sequencing with an ABI 3730XL Genetic Analyzer (Applied Biosystems; Thermo Fisher Scientific, Inc.), which was performed by Invitrogen Trading (Shanghai) Co., Ltd., the variable sequences were compared with germline gene segments using Basic Local Alignment Search Tool in the National Center for Biotechnology Information (NCBI) database (https://blast.ncbi.nlm.nih.gov/Blast.cgi).

Small interfering (si)RNA transfection. Synthetic siRNA targeting the human $\operatorname{Ig} \gamma$ chain constant region and control siRNAs were purchased from Shanghai GenePharma Co., Ltd. (Shanghai, China). The siRNA sequences were as follows, siRNA-1, 5'-GCAAGGAGUACAAGUGCAATT-3', siRNA-2, 5'-CCGGAGAACAACUACAAGATT-3', siRNA-3, 5'-CACAACCACUACACACAGATT-3', siRNA-positive control, 5'-UGACCUCAACUACAUGGUU-3', siRNA-nega- tive control, 5'-UUCUCCGAACGUGUCACGUTT-3'. Lipofectamine 3000 transfection reagent (Invitrogen; Thermo Fisher Scientific, Inc.) was used to transfect the siRNAs into the podocyte cell line. Following transfection, which was conducted according to the manufacturer's protocol, the knockdown efficiency was detected by western blotting. Approximately $3 \times 10^{5}$ cells/well were cultured in complete medium with a final siRNA concentration of $50 \mathrm{nM}$. The cells were transfected at $37^{\circ} \mathrm{C}$ for $48 \mathrm{~h}$ and subsequently collected for further experiments.

Cell viability assay. Cell viability was measured by Cell Counting kit-8 (CCK-8; Dojindo Molecular Technologies, Inc., Kumamoto, Japan). Briefly, cells from each siRNA group were seeded into 3 wells of a 96-well plate for $48 \mathrm{~h}$ at $37^{\circ} \mathrm{C}(1,000-2,000$ cells per well). Subsequently, the medium was replaced with $100 \mu \mathrm{l}$ fresh culture medium containing $8 \mu \mathrm{l}$ CCK-8 reagent. After incubation for $2 \mathrm{~h}$ at $37^{\circ} \mathrm{C}$, a spectrophotometric microplate reader (BioTek Instruments, Inc., Winooski, VT, USA) was used to measure the absorbance at $450 \mathrm{~nm}$; cell viability was indirectly reflected.

Cell adhesion assay. To analyze the adhesive ability of the cells, a CCK-8 assay (Dojindo Molecular Technologies, Inc.) was conducted following siRNA transfection for $48 \mathrm{~h}$. Briefly, $1 \times 10^{4}$ cells resuspended in $100 \mu 1$ media were seeded in each well of a 96 -well plate and were incubated at $37^{\circ} \mathrm{C}$ for $1 \mathrm{~h}$. Each group (3 wells per group) including siRNA-1, siRNA-2, siRNA-3, siRNA-NC, mock and blank, was divided into 3 groups: washed, unwashed and blank group. In the washed group, the cells were washed gently with PBS three times and $100 \mu 1$ fresh media with $8 \mu \mathrm{l}$ CCK- 8 reagent was added to the wells. In the unwashed group, the cells were added with $100 \mu \mathrm{l}$ fresh media with $8 \mu \mathrm{l}$ CCK-8 reagent. In the blank group, CCK-8 was directly added into the wells without cells. After incubation for $2 \mathrm{~h}$ at $37^{\circ} \mathrm{C}$, the adhered cells were determined by detecting the absorbance at $450 \mathrm{~nm}$ using a spectrophotometric microplate reader (BioTek Instruments, Inc.). Cell adhesion was determined using the following formula:

$$
\text { Cell adhesion rate }=\frac{\mathrm{OD}_{\text {washed }}-\mathrm{OD}_{\text {blank }}}{\mathrm{OD}_{\text {unwashed }}-\mathrm{OD}_{\text {blank }}}
$$

Statistical analysis. Data are expressed as the means \pm standard deviation and were analyzed by SPSS 20.0 software (IBM Corp., Armonk, NY, USA). All experiments were repeated 3 times. To determine significant differences between two groups, Student's t-test was used. The significant differences between more than two groups were analyzed using one-way analysis of variance and a least significant difference multiple comparison test. $\mathrm{P}<0.05$ was considered to indicate a statistically significant difference.

\section{Results}

IgG heavy and light chains were stained in human podocytes by immunofluorescence staining. To determine the expression of $\mathrm{IgG}$ in podocytes, the present study conducted an immunofluorescence analysis using commercially available 

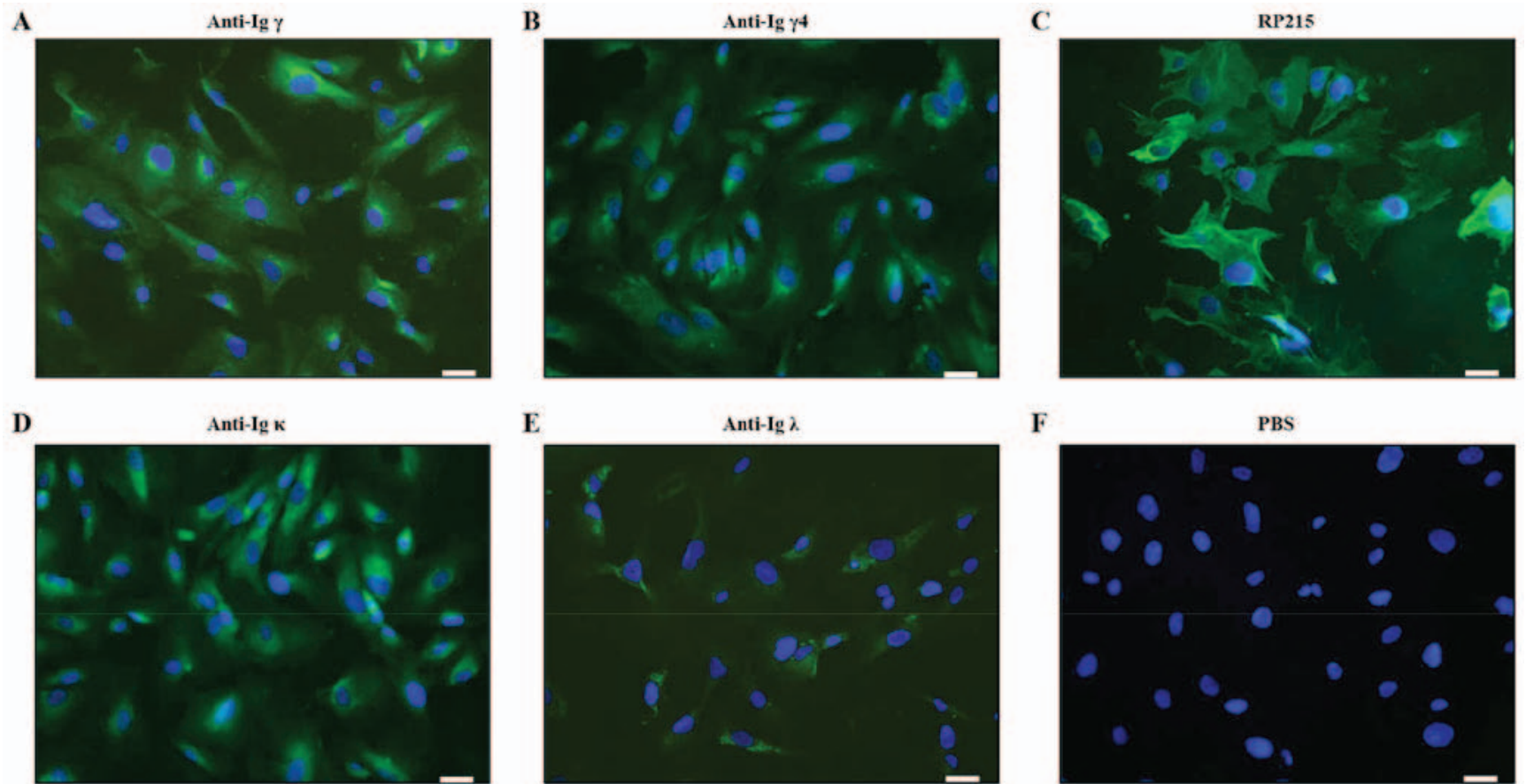

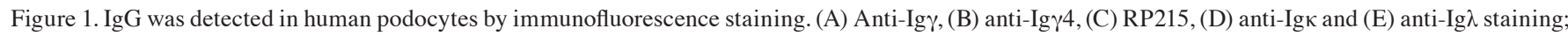
(F) PBS was used as a negative control. Igs were immunostained (green) and nuclei were stained with DAPI (blue). Scale bar, $50 \mu \mathrm{m}$. IgG, immunoglobulin G; $\operatorname{Ig} \gamma, \operatorname{IgG}$ heavy chain.

anti-human $\operatorname{Ig} \gamma, \operatorname{Ig} \gamma 1-4, \operatorname{Ig} \kappa$ and $\operatorname{Ig} \lambda$ light chain antibodies; and RP215 mAb, which recognizes non-B cell-derived Ig $\gamma$ (34) (Fig. 1). Positive staining of $\operatorname{Ig} \gamma, \gamma 4, \kappa$ and $\lambda$ was detected in the cytoplasm of podocytes (Fig. 1A, B, D and E). However, $\operatorname{Ig} \gamma 2$ and $\operatorname{Ig} \gamma 3$ staining was not found by immunofluorescence staining. Stronger positive staining of RP215 was predominantly localized in the cytoplasm and on the cell membrane of podocytes (Fig. 1C).

Confirmation of the expression of $\operatorname{Ig} G$ in podocytes by western blotting and mass spectrometry. To confirm the expression of corresponding proteins, IgG heavy and light chains were detected in podocyte cell lysates and culture supernatants by western blotting. Human serum that contains a substantial amount of Igs was used as a positive control. In order to eliminate the interference of FBS in the media, FBS in electrophoresis was blotted with anti-human $\operatorname{Ig} \gamma, \kappa$ and $\lambda$ antibodies and negatively stained. The commercial anti-Ig $\gamma$ antibody and $\mathrm{RP} 215 \mathrm{mAb}$ detected Ig $\gamma$ at $55 \mathrm{kDa}$. In addition, subclasses of Ig $\gamma$, including $\operatorname{Ig} \gamma 1$ (52 kDa), Ig 33 (58 kDa), Ig $\gamma 4$ (36 kDa), were detected and the bands obtained were consistent with the predicted molecular weight, or the detected bands in the antibody instructions. However, $\operatorname{Ig} \gamma 2$ expression was not found after several experiments. Furthermore, $\operatorname{Ig} \kappa(25 \mathrm{kDa})$ and $\operatorname{Ig} \lambda$ $(50 \mathrm{kDa})$ expression was observed in the cell lysate (Fig. 2A).

To further verify the secretion of IgG by podocytes, IgG was extracted from the culture supernatant using protein $G$ beads, which bind to human IgG with high specificity. The protein in the eluate was recognized at $150 \mathrm{kDa}$ and $55 \mathrm{kDa}$, following incubation with an anti-human IgG antibody. These weights correspond with the weight of the intact tetramer at $150 \mathrm{kDa}$ and that of the single $\gamma$ chain at $55 \mathrm{kDa}$ (Fig. 2B). Mass spectrometry demonstrated that the $150 \mathrm{kDa}$ band contained segments of the $\operatorname{Ig} \gamma 1$ chain constant region and $\operatorname{Ig} \lambda$ chain VLJ region, according to the NCBI database (Fig. 2C), and the Ig $\gamma 1$ chain constant region could be found at $55 \mathrm{kDa}$.

Transcription of IgG heavy and light chain constant regions and related enzymes in podocytes. The expression levels of IgG genes and associated enzymes were explored in podocytes by RT-PCR. The B lymphocyte marker CD19 was used to exclude the possible contamination of B lymphocytes. CD19 expression was positive in the PBMC control group, but not in the podocyte group. The mRNA expression levels of $\operatorname{Ig} \gamma, \kappa$ and $\lambda$ constant regions, and the $\operatorname{Ig} \gamma$ subclasses, including $\operatorname{Ig} \gamma 1, \gamma 3$ and $\gamma 4$ constant regions were detected (Fig. 3A), whereas $\operatorname{Ig} \gamma 2$ was not; these results were similar to those of western blotting.

Notably, the mRNA expression levels of AID, which is the essential element for somatic hypermutation and class switch recombination (CSR) in B lymphocytes, and of RAG1 and RAG2, which are necessary for $\mathrm{V}(\mathrm{D}) \mathrm{J}$ rearrangement, were detected in human podocytes (Fig. 3B), thus indicating that class switching of $\operatorname{Ig} \gamma$ and gene rearrangement of the variable region may occur in podocytes.

After sequencing, the sequences of PCR products were aligned with the mRNA sequences available in the NCBI database; homologies between 96 and 99\% were demonstrated (Fig. 3C).

$V(D) J$ rearrangement of the IgG variable region and rearrangement patterns. $\mathrm{V}(\mathrm{D}) \mathrm{J}$ rearrangements take place at the genomic level prior to the expression of corresponding proteins in B lymphocytes. By using semi-nested RT-PCR and DNA sequence analysis, the present study identified gene recombination sequences of $\mathrm{IgG}$ heavy and light chains in podocytes (Fig. 3A). T-A cloning and sequencing demon- 
Table II. IGHV/IGHD/IGHJ rearrangement patterns of the Ig heavy chain variable region in podocytes and PBMCs.

\begin{tabular}{|c|c|c|c|}
\hline Name of cells & $\begin{array}{l}\text { No. of } \\
\text { clones }\end{array}$ & IGHV/IGHD/IGHJ usage & $\begin{array}{l}\text { Identity with } \\
\text { germlines }(\%)\end{array}$ \\
\hline \multirow[t]{3}{*}{ Podocytes (NC) } & 12 & IGHV3-23*01/IGHD3-22*01/IGHJ4*02 & $88.8-90.6$ \\
\hline & 8 & IGHV3-23*01/IGHD3-16*02/IGHJ4*02 & $85.9-87.0$ \\
\hline & 2 & IGHV3-23*01/IGHD4-17"01/IGHJ6*03 & $89.0-91.6$ \\
\hline \multirow[t]{4}{*}{ Podocytes (SAC) } & 6 & IGHV3-23*01/IGHD1-7*01/IGHJ6*03 & $91.6-94.8$ \\
\hline & 6 & IGHV3-23*01/IGHD2-8*01/IGHJ6*02 & $84.6-86.3$ \\
\hline & 10 & IGHV3-30-3*03/IGHD3-16*02/ IGHJ6*02 & $88.0-90.1$ \\
\hline & 1 & IGHV3-30-3*01/IGHD2-15*01/ IGHJ4*02 & 96.9 \\
\hline \multirow[t]{6}{*}{ PBMCs (control) } & 1 & IGHV5-51*01/IGHD3-22*01/IGHJ3*02 & 96.9 \\
\hline & 1 & IGHV3-7*03/IGHD1-26*01/IGHJ4*02 & 92.3 \\
\hline & 1 & IGHV3-11*05/IGHD1-26*01/IGHJ4*02 & 95.4 \\
\hline & 1 & IGHV6-1*02/IGHD5-24*01/IGHJ4*02 & 93.9 \\
\hline & 1 & IGHV3-33*03/IGHD5-24*01/IGHJ6*03 & 96.9 \\
\hline & 1 & IGHV3-7*01/IGHD3-16*02/IGHJ4*02 & 91.7 \\
\hline
\end{tabular}

Ig, immunoglobulin; NC, negative control; PBMCs, peripheral blood mononuclear cells; SAC, Staphylococcus aureus.

$\mathbf{A}$

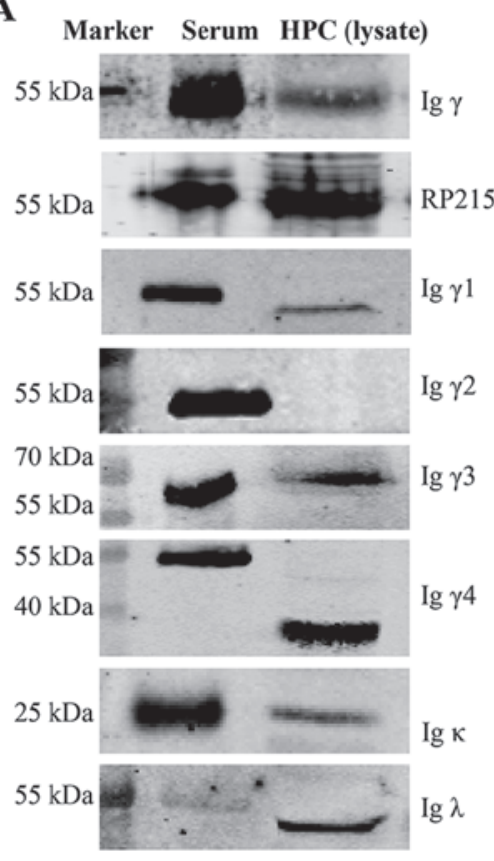

B

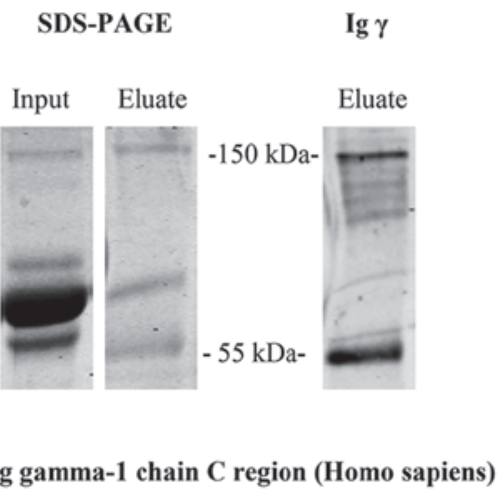

1 ASTKGPSVFP LAPSSKSTSG GTAALGCLVK DYFPEPVTVS WNSGALTSGV HTFPAVLQSS 61 GLYSLSSVVT VPSSSLGTQT YICNVNHKPS NTKVDKKVEP KSCDKTHTCP PCPAPELLGG 121 PSVFLFPPKP KDTLMISRTP EVTCVVVDVS HEDPEVKFNW YVDGVEVHNA KTKPREEQYN 181 STYRVVSVLT VLHQDWLNGK EYKCKVSNKA LPAPIEKTIS KAKGQPREPQ VYTLPPSRDE 241 LTKNQVSLTC LVKGFYPSDI AVEWESNGQP ENNYKTTPPV LDSDGSFFLY SKLTVDKSRW 301 QQGNVFSCSV MHEALHNHYT QKSLSLSPGK

Ig lambda light chain VLJ region, partial (Homo sapiens)

1 MKYLLPTAAA GLLLLAAQPA MAHVILTQPA SVSGSPGQSI TISCTGTSSD IGTYNVVSWY 61 QQHPGNAPKL MIYDVTRRPS GVSDRFSGSK SGNTASLTIS GLQAEDETDY YCCSYAGSEN 121 HYLFGSGTKV TVLGQPKANP TVTLFPPSSE ELQANKATLV CLISDFYPGA VTVAWKADGS 181 PVKAGVETTK PSKQSNNKYA ASSYLSLTPE QWKSHRSYSC QVTHEGSTVE KTVAPTECSA 241 RQSTPFVCEY QGQSSDLPQP PVNAGGGSGG GSGGG

Figure 2. Expression of IgG in cell lysate and supernatant of podocytes. (A) Ig $\gamma$ expression in the cell lysate was detected using a commercial anti-Ig $\gamma$ antibody and RP215 monoclonal antibody with western blotting. Ig $\kappa$, Ig $\lambda$, subclasses of $\operatorname{Ig} \gamma$, with the exception of Ig $\gamma 2$, were also detected using commercial antibodies Serum from a healthy subject was used as a positive control. (B) Ig $\gamma$ was purified from the cell supernatant by affinity chromatography using protein G sepharose; serum from a healthy subject was used as a positive control. (C) Mass spectrometry results. Bold sequences refer to the alignment of an amino acid sequence with Ig $\gamma 1$ chain constant region protein and Ig $\lambda$ chain VLJ region in the National Center for Biotechnology Information database. HPC, human podocytes; IgG, immunoglobulin G; Ig $\gamma$, IgG heavy chain.

strated that the $\operatorname{Ig} \gamma$ and $\operatorname{Ig} \kappa$ genes from clones had typical $\mathrm{V}(\mathrm{D}) \mathrm{J}$ rearrangements, with the V-D, D-J or V-J junctions (data not shown). All sequences obtained were productive and there were no stop codons in each region.
Notably, in contrast to the diverse gene rearrangements in B lymphocytes, the present study detected conservative $\mathrm{V}(\mathrm{D}) \mathrm{J}$ patterns in podocyte-derived Ig, with VH3-23/D3-22/JH4 (12/22), VH3-23/D3-16/JH4 (8/22) and VH3-23/D4-17/JH6 (2/22) as the predominant rear- 

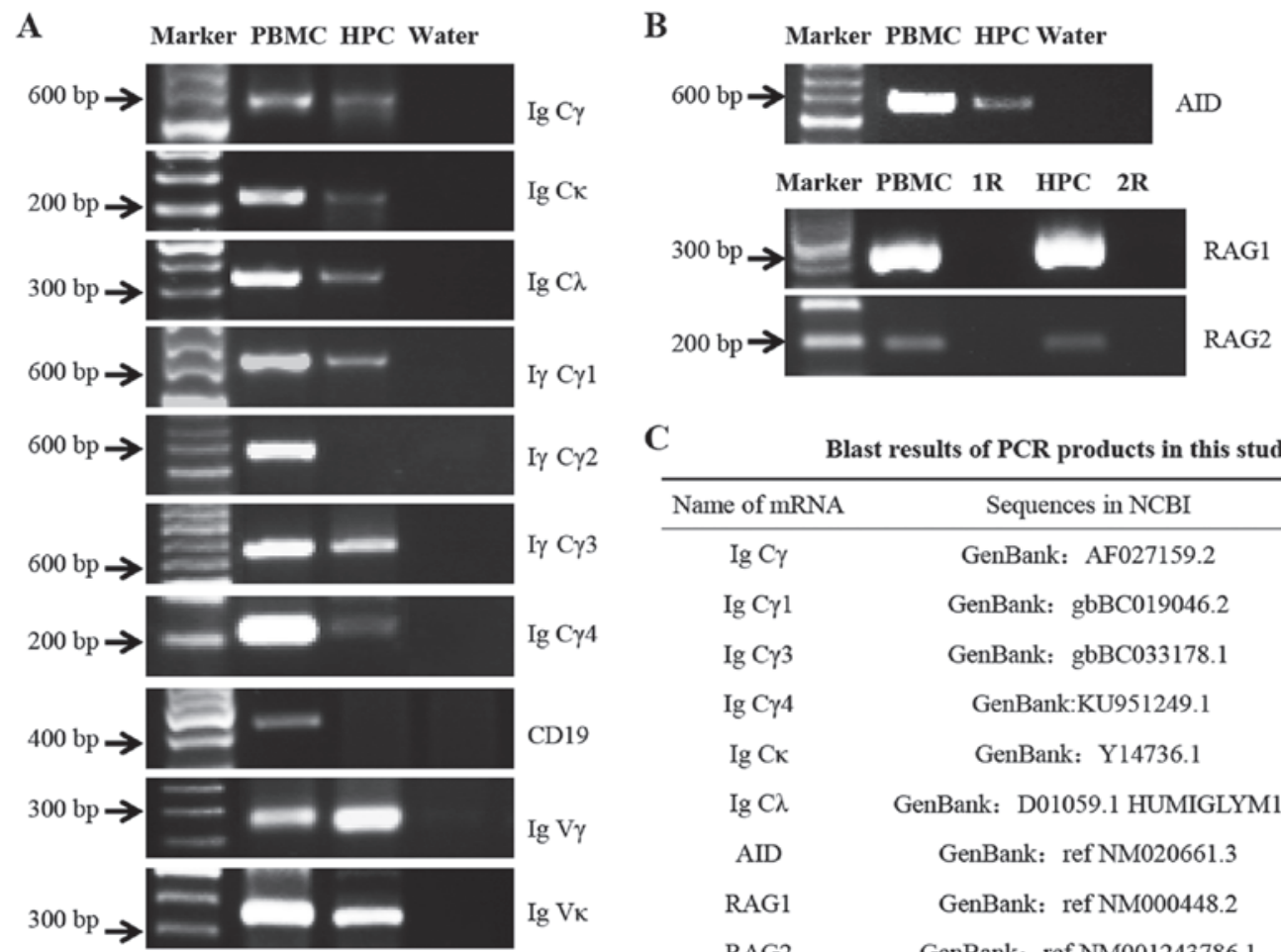

\begin{tabular}{ccc} 
C & \multicolumn{3}{c}{ Blast results of PCR products in this study } \\
\hline Name of mRNA & Sequences in NCBI & Identity(\%) \\
\hline Ig C $\gamma$ & GenBank: AF027159.2 & $96 \%$ \\
Ig C $\gamma 1$ & GenBank: gbBC019046.2 & $99 \%$ \\
Ig C $\gamma 3$ & GenBank: gbBC033178.1 & $99 \%$ \\
Ig C $\gamma 4$ & GenBank:KU951249.1 & $98 \%$ \\
Ig CK & GenBank: Y14736.1 & $98 \%$ \\
Ig C $\lambda$ & GenBank: D01059.1 HUMIGLYM1 & $98 \%$ \\
AID & GenBank: ref NM020661.3 & $97 \%$ \\
RAG1 & GenBank: ref NM000448.2 & $99 \%$ \\
RAG2 & GenBank: ref NM001243786.1 & $99 \%$ \\
\hline
\end{tabular}

Figure 3. Detection of the mRNA expression levels of IgG and related enzymes, including RAG1, RAG2 and AID in podocytes. (A) Transcripts of Ig $\gamma, \gamma 1, \gamma 3, \gamma 4, \kappa$ and $\lambda \mathrm{C}$ regions were detected by RT-PCR. CD19 was detected as a marker of B lymphocytes. The mRNA of Ig $\gamma$ and $\kappa$ V regions was amplified by nested RT-PCR. (B) mRNA expression levels of AID, RAG1 and RAG2. PBMCs were used as a positive control; water instead of cDNA was used as a blank control; R (cDNA template replaced by DNase-treated RNA) was used as negative control. (C) DNA sequencing results. The sequences of the PCR products were aligned with the mRNA sequences available in the NCBI database. HPC, human podocytes; AID, activation-induced cytidine deaminase; C, constant; Ig, immunoglobulin; Ig $\gamma$, IgG heavy chain; PBMCs, peripheral blood mononuclear cells; RAG. recombination activating gene; RT-PCR, reverse transcription-polymerase chain reaction; V, variable.

Table III. IGKV/IGKJ rearrangement patterns of the Igא variable region in podocytes and PBMCs.

\begin{tabular}{lccc}
\hline $\begin{array}{l}\text { Name of } \\
\text { cells }\end{array}$ & $\begin{array}{c}\text { No. of } \\
\text { clones }\end{array}$ & $\begin{array}{c}\text { IGKV/IGKJ } \\
\text { usage }\end{array}$ & $\begin{array}{c}\text { Identity } \\
\text { with } \\
\text { germlines (\%) }\end{array}$ \\
\hline $\begin{array}{l}\text { Podocytes } \\
\text { (NC) }\end{array}$ & 10 & IGKV1-39*01/IGKJ1*01 & $92.9-93.6$ \\
Podocytes & 3 & IGKV1-39*01/IGKJ1*01 & $90.1-90.5$ \\
(SAC) & 8 & IGKV1-12*01/IGKJ4*01 & $90.1-95.3$ \\
PBMC & 1 & IGKV1-9*01/IGKJ1*01 & 91.5 \\
(control) & 1 & IGKV1-12*01/IGKJ402 & 83.5 \\
& 1 & IGKV1-39*01/IGKJ2*02 & 95.3 \\
& 1 & IGKV1-39*01/IGKJ5*01 & 88.0 \\
& 1 & IGKV2-29*02/IGKJ2*01 & 94.7 \\
& 2 & IGKV4-1*01/IGKJ2*01 & 98.0 \\
& 2 & IGKV4-1*01/IGKJ3*01 & 96.4 \\
& 1 & IGKV4-1*01/IGKJ4*01 & 92.7 \\
\hline
\end{tabular}

Ig, immunoglobulin; NC, negative control; PBMCs, peripheral blood mononuclear cells; SAC, Staphylococcus aureus.

rangements in the $\gamma$ chain variable region (Table II), and

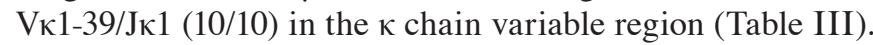

SAC upregulates the expression of IgG and alters the conservative variable regions in podocytes. A total of $48 \mathrm{~h}$ after stimulation with SAC, $\operatorname{Ig} \gamma, \gamma 4$ and $\lambda$ were significantly upregulated $(\mathrm{P}<0.05)$, and the mRNA expression levels of the $\operatorname{Ig} \gamma$ and Ig $\kappa$ variable regions were increased, thus indicating that SAC upregulated the expression of IgG in podocytes (Fig. 4). Furthermore, the conservative rearrangements in the variable regions were altered following SAC incubation. In the SAC group, VH3-23/D1-7/JH6, VH3-23/D2-8/JH6 and VH3-30/ D3-16/JH6 rearrangements were found in the $\gamma$ chain variable

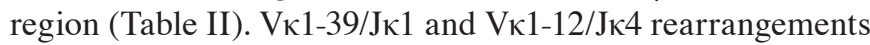
were found in the $x$ chain variable region (Table III)..

Downregulation of IgG following siRNA transfection, and its role in cell viability and adhesion. The present study used three siRNAs (siRNA 1-3) against the $\operatorname{Ig} \gamma$ chain constant region. A total of $48 \mathrm{~h}$ post-transfection, western blot analysis was used to detect Ig $\gamma$ expression. The protein expression levels of $\operatorname{Ig} \gamma$ were significantly reduced in podocytes by siRNA-1 (Fig. 5A), thus indicating that siRNA-1 was effective.

To further confirm the involvement of podocyte-derived $\mathrm{IgG}$ in podocyte function, the alterations in cell morphology, viability and adhesion were detected in each group. Immunofluorescence assay using F-actin staining demonstrated that cell volume was reduced and morphology was altered in response to $\operatorname{IgG}$ expression knockdown in the siRNA-1 group (Fig. 5B). Furthermore, in the siRNA-1 
A
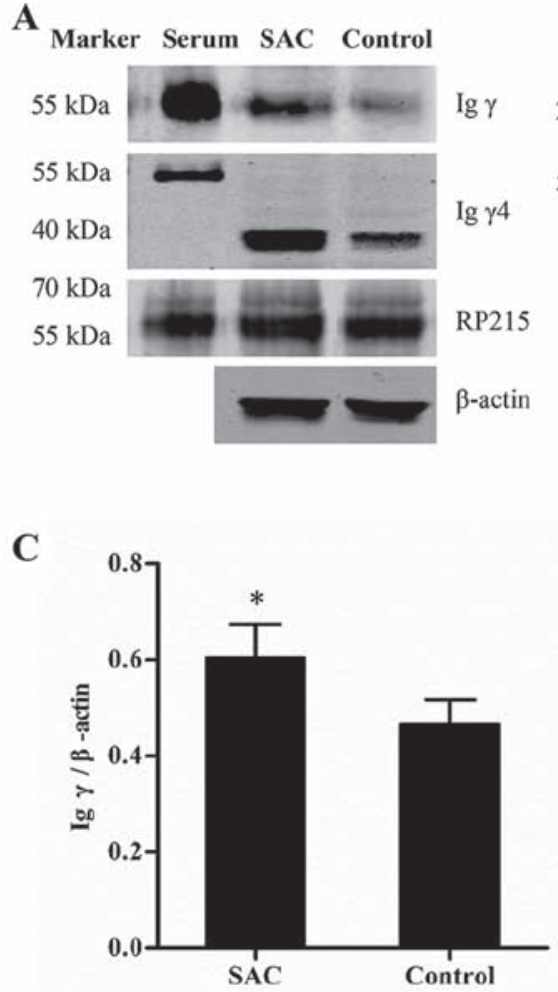

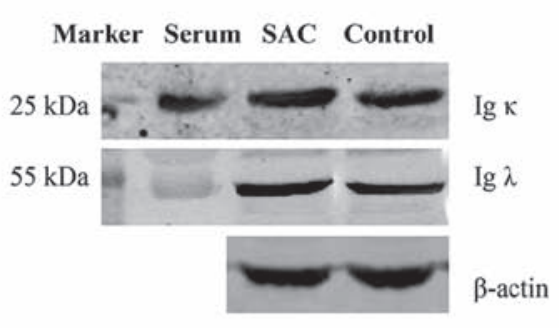

B

PBMC SAC Control Water
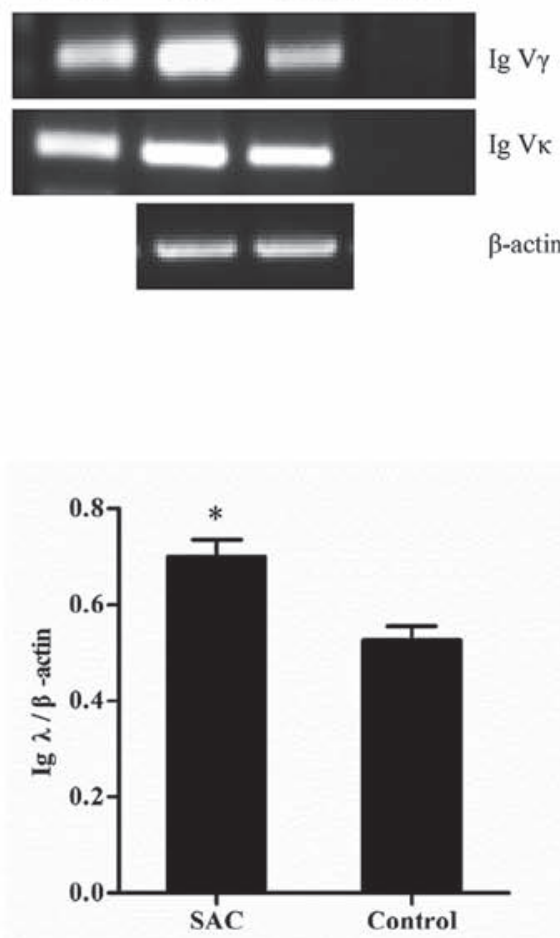

Figure 4. IgG expression in the podocyte cell lysate was increased following SAC treatment for $48 \mathrm{~h}$. (A) Western blot analysis of the protein expression levels of $\operatorname{Ig} \gamma, \gamma 4, \kappa$ and $\lambda$. (B) mRNA expression levels of the $\operatorname{Ig} \gamma$ and $\operatorname{Ig} \kappa \mathrm{V}$ regions were evaluated by reverse transcription-polymerase chain reaction. (C) Expression levels of Ig $\gamma, \gamma 4$ and $\lambda$ were evaluated and semi-quantified according to the expression of the internal control. $\beta$-actin was used as an internal control. Data are presented as the means \pm standard deviation, $\mathrm{n}=3$. ${ }^{*} \mathrm{P}<0.05$. Ig, immunoglobulin; Ig $\gamma$, IgG heavy chain; PBMC, peripheral blood mononuclear cells; SAC, Staphylococcus aureus; V, variable.

group, viability was reduced compared with in the other groups, including siRNA-NC, Mock and Blank $(1.05 \pm 0.05$ vs. $1.37 \pm 0.02,1.32 \pm 0.04$ and $1.47 \pm 0.03$, respectively) $(\mathrm{P}<0.01)$. In addition, adhesive capability was significantly reduced in the siRNA-1 group compared with in the other groups, including siRNA-NC, Mock and Blank $(0.37 \pm 0.05$ vs. $0.56 \pm 0.03,0.52 \pm 0.03$ and $0.65 \pm 0.05 \%$ ) (Fig. $5 \mathrm{C}$ and D) $(\mathrm{P}<0.01)$, as determined by CCK-8 assay.

\section{Discussion}

The present study detected the expression levels of IgG heavy and light chains at the protein and mRNA levels in podocytes. The results demonstrated that the expression was associated with cell viability and adhesion.

Firstly, the present study used immunofluorescence to determine the expression and distribution of $\operatorname{Ig} \gamma, \gamma 1-4$ heavy chains, and $\kappa$ and $\lambda$ light chains in podocytes. Positive staining of $\operatorname{Ig} \gamma, \gamma 4, \kappa$ and $\lambda$ chains was detected in the cytoplasm of podocytes, thus indicating that podocytes may express IgG. Shao et al (35) reported that IgM was expressed and presented in kidney tubules in $\mu \mathrm{MT}$ mice, which have hardly any IgM in circulation due to the disruption of the $\mu$ heavy chain, thus lacking mature B cells. Compared with commercial antibodies, the RP215 antibody recognizes a specific carbohydrate-associated epitope on non-B cell-derived $\operatorname{Ig} \gamma$ (34); in the present study, RP215 mAb detected IgG more clearly both on the cell membranes and in the cytoplasm, suggesting that podocyte-derived $\mathrm{IgG}$ was more likely to be non-B cell derived as the findings of Liao et al (26). The positive staining of $\operatorname{Ig} \gamma 4$ is consistent with the fact that $\mathrm{IgG} 4$ is the predominant subtype of immune complexes in MN, which is the most common cause of adult nephrotic syndrome (3).

Western blotting confirmed that the $\operatorname{Ig} \gamma$ protein band was recognized by a commercial anti-Ig $\gamma$ antibody at $55 \mathrm{kDa}$, thus indicating that podocyte-derived Ig may have a similar molecular size to that in circulation. Similar to the immunofluorescence findings, RP215 mAb binding suggested that podocyte-derived IgG was more similar to non-B cell-derived IgG and contained a unique glycosylated epitope (25). In addition, the present study detected subclasses of $\operatorname{Ig} \gamma$, with $\operatorname{Ig} \gamma 1$ and $\gamma 3$ located at 52 and $58 \mathrm{kDa}$, respectively, which were near the molecular weight of $\operatorname{Ig} \gamma$ in the serum. $\operatorname{Ig} \gamma 4$ was located at $36 \mathrm{kDa}$, which was consistent with the predicted molecular weight in the antibody instructions. Furthermore, Ig $\kappa$ in the podocyte lysate had the same weight as in the serum at $25 \mathrm{kDa}$, whereas $\operatorname{Ig} \lambda$ was detected at $50 \mathrm{kDa}$, just two times the weight of a single $\lambda$ chain, which may be attributable to modification or polymerization. To determine if podocytes secreted IgG, protein $\mathrm{G}$ sepharose and affinity chromatography were conducted; IgG with a molecular weight of $150 \mathrm{kDa}$, as an intact tetramer, and $55 \mathrm{kDa}$, as a single heavy chain, were obtained in the supernatant. Mass spectrometry indicated that the $150 \mathrm{kDa}$ band contained segments of $\operatorname{Ig} \gamma 1$ constant region and $\lambda$ chain, whereas the $55 \mathrm{kDa}$ band contained peptides from the $\operatorname{Ig} \gamma 1$ chain constant 

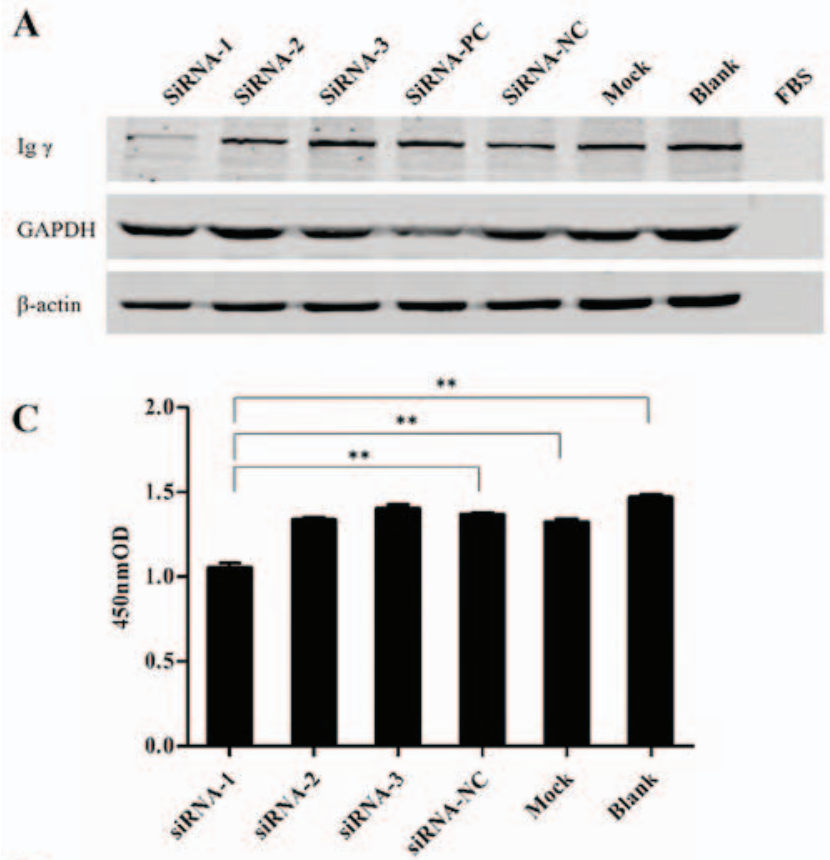

D

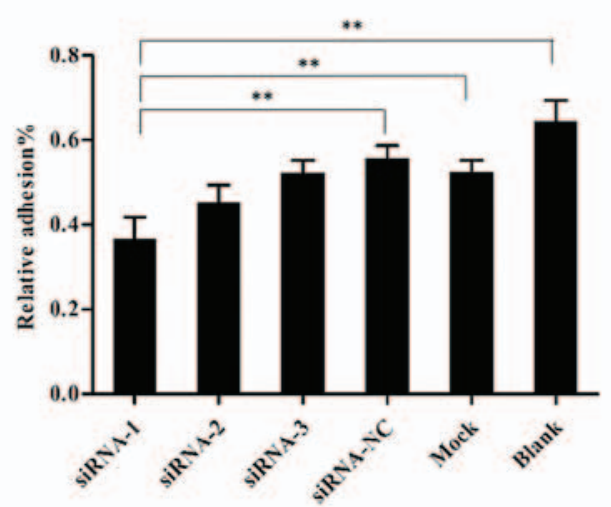

B
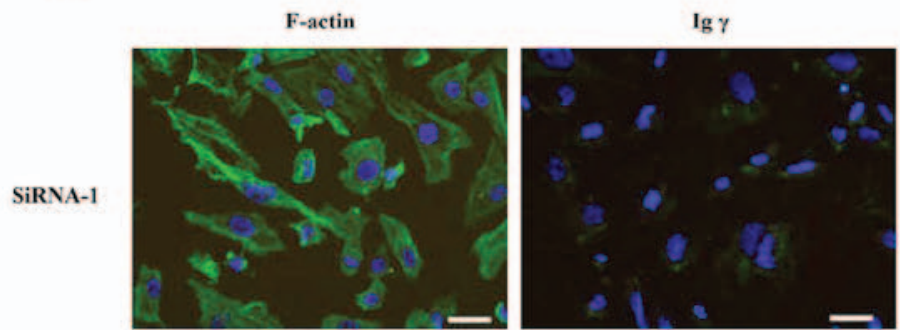

SiRNA-2
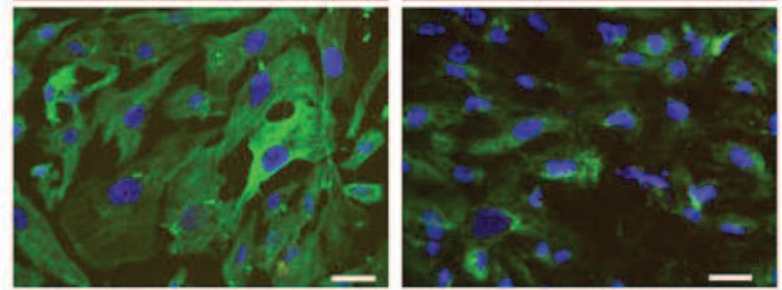

SiRNA-3
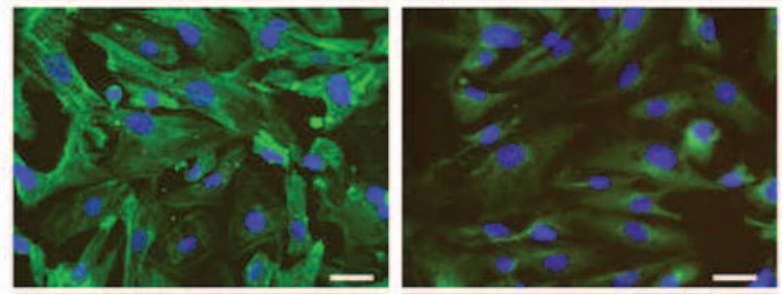

SiRNA-NC
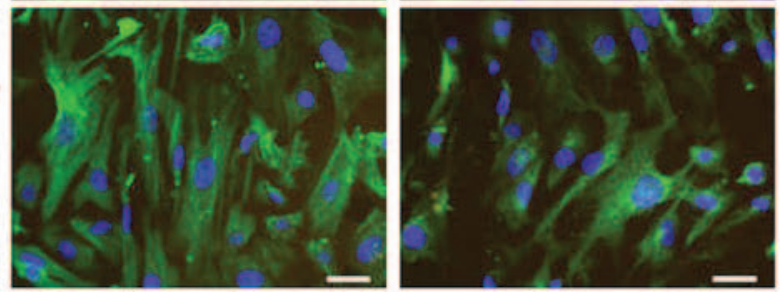

Figure 5. IgG expression $48 \mathrm{~h}$ post-transfection with siRNA. (A) Western blot analysis confirmed successful knockdown of IgG in podocytes by siRNAs. GAPDH was used as a positive control. (B) Immunofluorescence assay of F-actin and Ig $\gamma$ staining. F-actin and IgG were immunostained (green), and nuclei were stained with DAPI (blue).(C) CCK-8 analysis of cell viability. (D) CCK-8 analysis of the adhesive ability of podocytes. siRNA-1, siRNA-2 and siRNA-3, siRNAs targeted the Ig $\gamma$ constant region; siRNA-PC, siRNA targeted GAPDH; siRNA-NC, scrambled siRNA; mock, cells treated with only Lipofectamine 3000; blank, untreated cells; FBS, culture medium without cells. Scale bar, $50 \mu \mathrm{m}$. Data are presented as the means \pm standard deviation, $\mathrm{n}=3$. ${ }^{* *} \mathrm{P}<0.01$. CCK-8, Cell Counting kit-8; FBS, fetal bovine serum; Ig, immunoglobulin; Ig $\gamma$, IgG heavy chain; NC, negative control; OD, optical density; PC, positive control.

region, further suggesting that podocytes may synthesize and secrete full length $\mathrm{IgG}$.

Ig gene recombination and transcription are prerequisites for protein production. In the present study, we first eliminated B lymphocyte contamination by detecting the CD19 expression and then obtained the positive amplification of the mRNA of Ig $\gamma, \gamma 1, \gamma 3, \gamma 4$ subclasses, $\kappa$ and $\lambda$ constant regions. After DNA sequencing, the PCR products conformed to the Ig mRNA sequences contained in the NCBI database, indicating that transcription of the $\mathrm{IgG}$ gene occurs in podocytes. During the process of B lymphocyte development, the variable region of the $\mathrm{IgG}$ heavy and light chains undergoes rearrangement, thus generating antibody diversity (36). Furthermore, podocytes have the ability to amplify functional transcripts of $\operatorname{Ig} \gamma$ and $\kappa$ light chain variable regions. The present study compared the podocyte-derived $\mathrm{V}(\mathrm{D}) \mathrm{J}$ rearrangements of $\mathrm{Ig}$ transcripts with conventional
$\mathrm{V}(\mathrm{D}) \mathrm{J}$ rearrangements in B cells. Although they displayed some common characteristics, including different junctions between V-D, D-J or V-J segments, numerous gene rearrangement differences existed between podocytes and B lymphocytes. Firstly, podocyte-derived $\operatorname{Ig} \gamma$ and $\kappa$ chains exhibited restricted rearrangement patterns compared with $\mathrm{B}$ cells, which exhibit Ig diversity; this result is in accordance with the findings of other studies $(12,18)$. Secondly, more common $\mathrm{V}$ segments were detected in podocyte as the VH3 gene family was present in all clones with $\mathrm{VH} 3-23$ positive in 34 clones (75.6\%) and VH3-30 in 11 clones (24.4\%), which was similar to the reports of Glanville et al (37). Finally, some stimulating factors, including SAC may alter the selection trends of rearrangement patterns in podocytes.

Gene rearrangement is initiated by RAG1 and RAG2 specifically binding to the recombination signal sequence. Subsequently, this compound cleaves DNA and induces the recombination of 
V, D and J segments (38). The present study detected RAG1 and RAG2 mRNA expression in human podocytes by nested RT-PCR, as in other studies $(6,9)$. When the body is stimulated by antigens, somatic hypermutation and CSR induce the generation of additional gene alterations. The present study demonstrated that transcription of AID, which is an important mediator of CSR and somatic hypermutation, exists in podocytes. These results indicated that V(D)J rearrangement and CSR may take place in podocytes, with a similar mechanism to in B lymphocytes.

Previous studies have suggested that non-B cell-derived Igs are associated with cell growth and proliferation $(6,23,24)$. In the kidney, cytoskeletal dynamics determine the correct morphology of podocytes, and the slit diaphragm complex, actin cytoskeleton and cell adhesion molecules form an intricate network to stabilize filtration barrier function $(39,40)$. Conversely, foot process fusion is a pathobiological manifestation of glomerular diseases, including MN. To investigate the association between IgG expression and cellular functions, siRNA targeting the $\operatorname{Ig} \gamma$ constant region was transfected into podocytes. In response to IgG knockdown, cell viability and adhesion were reduced, and alterations were detected in the actin cytoskeleton, thus indicating that $\mathrm{IgG}$ expression was associated with cellular bioactivities, including survival, proliferation and adhesion (6).

In conclusion, the present study demonstrated that human podocytes exhibit the capacity to produce $\mathrm{IgG}$, and IgG expression is significantly upregulated when podocytes are stimulated by SAC. In addition, downregulation of $\mathrm{IgG}$ may have negative consequences for cell survival, viability and adhesion. The present study is the first, to the best of our knowledge, to indicate that $\mathrm{IgG}$ may be expressed in podocytes and provides additional evidence to suggest that Igs may be produced in cells other than B lymphocytes. The potential role of podocyte-derived $\mathrm{IgG}$ in the pathogenesis of podocytic diseases, such as membranous nephropathy (MN), focal segmental glomerular sclerosis (FSGS), and its possible clinical application, require further investigation.

\section{Acknowledgements}

The authors would like to thank the Department of Immunology, Peking University, for supporting their work.

\section{Funding}

This study was supported by grants from the National Natural Science Foundation of China (91642109, 91229102 and 81272237).

\section{Availability of data and materials}

The data and materials described in the manuscript will be freely available to any scientist wishing to use them for noncommercial purposes.

\section{Authors' contributions}

As the corresponding authors, YW and XQ planned and supervized the study. ZJ participated in the research design, performed most experiments and wrote the manuscript. HD, $\mathrm{JM}$ and $\mathrm{YG}$, were partly involved in immunohistochemistry assay, western blot analysis and writing of the manuscript. YL, RW, LA and ZG provided suggestions and technical supports. All authors read and approved the final manuscript.

\section{Ethics approval and consent to participate}

The study was approved by the ethics committee of Peking University Third Hospital (approval document issued on February 17th, 2016; under no. 053). Human serum and PBMC, used as positive controls in both Western blot and RT-PCR tests in the study, were obtained from the blood of first author ZJ. Her results of blood pressure, blood routine, urine routine, liver function, kidney function, serum biochemical are normal. She knew the research well and was exempted from written informed consent.

\section{Consent for publication}

Not applicable.

\section{Competing interests}

The authors declare that they have no competing interests.

\section{References}

1. Reiser J and Altintas MM: Podocytes. F1000Research F1000 Faculty Rev 5: 114, 2016.

2. Wiggins RC: The spectrum of podocytopathies: A unifying view of glomerular diseases. Kidney Int 71: 1205-1214, 2007.

3. Beck LH Jr and Salant DJ: Membranous nephropathy: From models to man. J Clin Invest 124: 2307-2314, 2014.

4. Beck LH Jr, Bonegio RGB, Lambeau G, Beck DM, Powell DW, Cummins TD, Klein JB and Salant DJ: M-type phospholipase A2 receptor as target antigen in idiopathic membranous nephropathy. N Engl J Med 361: 11-21, 2009.

5. Schlumberger W, Hornig N, Lange S, Probst C, Komorowski L, Fechner K, Dähnrich C and Stöcker W: Differential diagnosis of membranous nephropathy with autoantibodies to phospholipase A2 receptor 1. Autoimmun Rev 13: 108-113, 2014.

6. Qiu X, Zhu X, Zhang L, Mao Y, Zhang J, Hao P, Li G, Lv P, Li Z, Sun X, et al: Human epithelial cancers secrete immunoglobulin $\mathrm{g}$ with unidentified specificity to promote growth and survival of tumor cells. Cancer Res 63: 6488-6495, 2003.

7. Li M, Feng DY, Ren W, Zheng L, Zheng H, Tang M and Cao Y: Expression of immunoglobulin kappa light chain constant region in abnormal human cervical epithelial cells. Int J Biochem Cell Biol 36: 2250-2257, 2004.

8. Babbage G, Ottensmeier CH, Blaydes J, Stevenson FK and Sahota SS: Immunoglobulin heavy chain locus events and expression of activation-induced cytidine deaminase in epithelial breast cancer cell lines. Cancer Res 66: 3996-4000, 2006.

9. Chen $\mathrm{Z}$ and $\mathrm{Gu}$ J: Immunoglobulin $\mathrm{G}$ expression in carcinomas and cancer cell lines. FASEB J 21: 2931-2938, 2007.

10. Qiu X, Sun X, He Z, Huang J, Hu F, Chen L, Lin P, You MJ, Medeiros LJ and Yin CC: Immunoglobulin gamma heavy chain gene with somatic hypermutation is frequently expressed in acute myeloid leukemia. Leukemia 27: 92-99, 2013.

11. Huang J, Sun X, Gong X, He Z, Chen L, Qiu X and Yin CC: Rearrangement and expression of the immunoglobulin $\mu$-chain gene in human myeloid cells. Cell Mol Immunol 11: 94-104, 2014.

12. Wang C, Xia M, Sun X, He Z, Hu F, Chen L, Bueso-Ramos CE, Qiu X and Yin CC: IGK with conserved IGKV/IGKJ repertoire is expressed in acute myeloid leukemia and promotes leukemic cell migration. Oncotarget 6: 39062-39072, 2015.

13. Huang J, Zhang L, Ma T, Zhang P and Qiu X: Expression of immunoglobulin gene with classical V-(D)-J rearrangement in mouse testis and epididymis. J Histochem Cytochem 57: 339-349, 2009.

14. Yan M, Zhang X, Pu Q, Huang T, Xie Q, Wang Y, Li J, Wang Y, $\mathrm{Gu} \mathrm{H}$, Huang $\mathrm{T}$, et al: Immunoglobulin g expression in human sperm and possible functional significance. Sci Rep 6: 20166, 2016. 
15. Huang J, Sun X, Mao Y, Zhu X, Zhang P, Zhang L, Du J and Qiu X: Expression of immunoglobulin gene with classical V-(D)-J rearrangement in mouse brain neurons. Int J Biochem Cell Biol 40: 1604-1615, 2008.

16. Niu N, Zhang J, Guo Y, Zhao Y, Korteweg C and Gu J: Expression and distribution of immunoglobulin $\mathrm{G}$ and its receptors in the human nervous system. Int J Biochem Cell Biol 43: 556-563, 2011.

17. Zhao Y, Liu Y, Chen Z, Korteweg C and Gu J: Immunoglobulin g (IgG) expression in human umbilical cord endothelial cells J Histochem Cytochem 59: 474-488, 2011.

18. Jiang D, Ge J, Liao Q, Ma J, Liu Y, Huang J, Wang C, $\mathrm{Xu} \mathrm{W}$, Zheng J, Shao W, et al: $\mathrm{IgG}$ and $\operatorname{IgA}$ with potential microbial-binding activity are expressed by normal human skin epidermal cells. Int J Mol Sci 16: 2574-2590, 2015.

19. Zheng J, Huang J, Mao Y, Liu S, Sun X, Zhu X, Ma T, Zhang L, Ji J, Zhang Y, et al: Immunoglobulin gene transcripts have distinct VHDJH recombination characteristics in human epithelial cancer cells. J Biol Chem 284: 13610-13619, 2009.

20. Lee $\mathrm{G}$ and Ge B: Cancer cell expressions of immunoglobulin heavy chains with unique carbohydrate-associated biomarker. Cancer Biomark 5: 177-188, 2009.

21. Lee $\mathrm{G}$ and $\mathrm{Ge} B$ : Inhibition of in vitro tumor cell growth by RP215 monoclonal antibody and antibodies raised against its anti-idiotype antibodies. Cancer Immunol Immunother 59: 1347-1356, 2010.

22. Wen YJ, Mancino A, Pashov A, Whitehead T, Stanley J and Kieber-Emmons T: Antigen binding of human IgG Fabs mediate ERK-associated proliferation of human breast cancer cells. DNA Cell Biol 24: 73-84, 2005.

23. Wang $J$, Lin $D$, Peng $H$, Huang $Y$, Huang $J$ and $G u J$ : Cancer-derived immunoglobulin $\mathrm{G}$ promotes tumor cell growth and proliferation through inducing production of reactive oxygen species. Cell Death Dis 4: e945, 2013.

24. Li M, Zheng H, Duan Z, Liu H, Hu D, Bode A, Dong Z and Cao Y: Promotion of cell proliferation and inhibition of ADCC by cancerous immunoglobulin expressed in cancer cell lines. Cell Mol Immunol 9: 54-61, 2012.

25. Liu Y, Liu D, Wang C, Liao Q, Huang J, Jiang D, Shao W, Yin CC, Zhang Y, Lee G, et al: Binding of the monoclonal antibody RP215 to immunoglobulin $\mathrm{G}$ in metastatic lung adenocarcinomas is correlated with poor prognosis. Histopathology 67 645-653, 2015

26. Liao Q, Liu W, Liu Y, Wang F, Wang C, Zhang J, Chu M, Jiang D, Xiao L, Shao W, et al: Aberrant high expression of immunoglobulin $\mathrm{G}$ in epithelial stem/progenitor-like cells contributes to tumor initiation and metastasis. Oncotarget 6: 40081-40094, 2015.

27. Liu H, Zheng H, Duan Z, Hu D, Li M, Liu S, Li Z, Deng X, Wang Z, Tang M, et al: LMP1-augmented kappa intron enhancer activity contributes to upregulation expression of Ig kappa light chain via NF-kappaB and AP-1 pathways in nasopharyngeal carcinoma cells. Mol Cancer 8: 92, 2009.
28. Zhu X, Wu L, Zhang L, Hao P, Zhang S, Huang J, Zheng J, Liu Y, Li W, Zhang Y, et al: Distinct regulatory mechanism of immunoglobulin gene transcription in epithelial cancer cells. Cell Mol Immunol 7: 279-286, 2010.

29. Wu L, Liu Y, Zhu X, Zhang L, Chen J, Zhang H, Hao P, Zhang S, Huang J, Zheng J, et al: The immunoglobulin heavy chain VH6-1 promoter regulates Ig transcription in non-B cells. Cancer Cell Int 14: 114, 2014.

30. Saleem MA, O'Hare MJ, Reiser J, Coward RJ, Inward CD, Farren T, Xing CY, Ni L, Mathieson PW and Mundel P: A conditionally immortalized human podocyte cell line demonstrating nephrin and podocin expression. J Am Soc Nephrol 13: 630-638, 2002

31. Cerutti A, Zan H, Schaffer A, Bergsagel L, Harindranath $\mathrm{N}$, Max EE and Casali P: CD40 ligand and appropriate cytokines induce switching to $\operatorname{IgG}, \operatorname{Ig} \mathrm{A}$, and $\operatorname{IgE}$ and coordinated germinal center and plasmacytoid phenotypic differentiation in a human monoclonal $\mathrm{IgM}^{+} \mathrm{IgD}^{+}$B cell line. J Immunol 160: 2145-2157, 1998.

32. Lynch S, Kelleher D, McManus R and O'Farrelly C: RAG1 and RAG2 expression in human intestinal epithelium: Evidence of extrathymic T cell differentiation. Eur J Immunol 25: 1143-1147, 1995.

33. Revy P, Muto T, Levy Y, Geissmann F, Plebani A, Sanal O, Catalan N, Forveille M, Dufourcq-Labelouse R, Gennery A, et al: Activation-induced cytidine deaminase (AID) deficiency causes the autosomal recessive form of the Hyper-IgM syndrome (HIGM2). Cell 102: 565-575, 2000.

34. Lee G, Huang C, Chow S and Chien C: Carbohydrate-associated epitope-based anti-cancer drugs and vaccines. Adv Biosci Biotechnol 4: 18-23, 2013.

35. Shao W, Zhang C, Liu E, Zhang L, Ma J, Zhu Z, Gong X, Qin Z and Qiu X: Identification of liver epithelial cell-derived Ig expression in $\mu$ chain-deficient mice. Sci Rep 6: 23669, 2016.

36. Tonegawa S: Somatic generation of antibody diversity. Nature 302: 575-581, 1983.

37. Glanville J, Zhai W, Berka J, Telman D, Huerta G, Mehta GR, Ni I, Mei L, Sundar PD, Day GM, et al: Precise determination of the diversity of a combinatorial antibody library gives insight into the human immunoglobulin repertoire. Proc Natl Acad Sci USA 106: 20216-20221, 2009.

38. Bassing $\mathrm{CH}$, Swat $\mathrm{W}$ and Alt FW: The mechanism and regulation of chromosomal V(D)J recombination. Cell 109 (Suppl 1): S45-S55, 2002

39. Welsh GI and Saleem MA: The podocyte cytoskeleton--key to a functioning glomerulus in health and disease. Nat Rev Nephrol 8: 14-21, 2011.

40. Nagata M: Podocyte injury and its consequences. Kidney Int 89: 1221-1230, 2016.

This work is licensed under a Creative Commons Attribution-NonCommercial-NoDerivatives 4.0 International (CC BY-NC-ND 4.0) License. 